\title{
Genetic Factors in Determining Bone Mass
}

\author{
David M. Smith, Walter E. Nance, Ke Won Kang, Joe C. Christian, \\ and C. ConRad Johnston, JR. \\ From the Indiana University School of Medicine, Indianapolis, Indiana 46202
}

A в TRACT This investigation was undertaken to evaluate possible genetic determinants of bone mass with the premise that inheritance of bone mass could be of etiologic importance in osteoporosis.

Bone mass and width measurements were made with the photon absorption technique on the right radius of 71 juvenile and 80 adult twin pairs. The variance of intrapair differences of bone mass in monozygotic (MZ) juvenile twins was $0.0013 \mathrm{~g}^{2} / \mathrm{cm}^{2}$ compared to $0.0052 \mathrm{~g}^{2} / \mathrm{cm}^{2}$ in the dizygotic (DZ) twins. For the adult twins the variance of intrapair differences in bone mass was 0.0069 for $\mathrm{MZ}$ and 0.0137 for $\mathrm{DZ}$ twins. Similar results were obtained for bone width. The aignificantly larger variation in intrapair differences in $\mathrm{DZ}$ twins indicates that these traits have significant genetic determinants. These intrapair differences were found to increase with age, suggesting that geneticenvironmental interaction also contributes to the observed variation in bone mass.

These data provide evidence that bone mass does have significant genetic factors, which alone or in conjunction with environmental factors may predispose persons to the development of osteoporosis.

\section{INTRODUCTION}

Many metabolic bone diseases characterized by high or low bone mass, such as osteogenesis imperfecta (1), vitamin D-resistant rickets (2), osteopetrosis (3), and pyknodysostosis (4), are known to have genetic bases. However, no investigations have been reported on the genetic factors in the etiology of senile or postmenopausal osteoporosis, a disease characterized by low bone mass and fractures.

In their review of osteoporosis, Newton-John and Morgan (5) have summarized the evidence that the

A preliminary report of a portion of this work has been published (Smith, D. M., C. C. Johnston, Jr., K. W. Kang, P. Winter, W. E. Nance. 1971. In vivo bone mass measurement in human twins. Clin. Res. $19: 486$.$) .$

Received for publication 27 April 1973 and in revised form 9 July 1973. total mass of bone present determines to a great extent the risk of fracture and that the loss of bone mass with age results in the increased frequency of fracture with age. It is appropriate, then, that both genetic and environmental factors that determine bone mass be examined in an attempt to gain some insight into the etiology of osteoporosis. Until recently, bone mass has been difficult to measure. However, precise in vivo estimates of bone mass can now be obtained by the photon absorption technique $(6,7)$, and thus it is possible to measure this major manifestation of osteoporosis objectively, as a continuous variable, and to investigate genetic influences on this trait.

Theoretically, inheritance could affect the development of osteoporosis in at least two ways. Genetic factors could influence the amount of bone mass attained at maturity, and subjects with genetically determined low bone mass then might be more susceptible to develop osteoporosis after entering the period of agedependent bone loss. Alternatively, or in conjunction with the above, genetic factors could influence the rate of bone loss. Under the latter model, subjects with a genetically determined accelerated bone loss would be more susceptible to osteoporosis. The purpose of this study was to investigate the first model, namely, the influence of genetic factors on bone mass.

Twin studies provide an efficient technique for detecting the influence of genetic factors on quantitative traits in man $(8,9)$. The method involves a comparison of intrapair differences of monozygotic $(\mathrm{MZ})^{1}$ twin pairs with intrapair differences of dizygotic (DZ) twins. Since MZ twins are genetically identical, their intrapair differences are assumed to arise exclusively from environmental factors. Intrapair differences in $\mathrm{DZ}$ twins, on the other hand, can arise because of both genetic and environmental differences. If a significantly larger variation of intrapair differences can be demonstrated in $\mathrm{DZ}$ twins, it may be inferred that

${ }^{1}$ Abbreviations used in this paper: $b$, regression coefficient; DZ, dizygotic; $h^{2}, H$, measure of heritability; $M$, mass; MZ, monozygotic; $W$, width. 
genetic factors make a significant contribution to the observed variation. We have obtained quantitative measurements of bone mass in a normal twin population in order to search for evidence that genetic factors influence this trait.

\section{METHODS}

Description of population surveyed. All available likesexed, juvenile twins attending the volunteer Twin Clinic at Indiana University Medical Center from 1970 through 1972 were surveyed. Adult veteran twins from the Indiana and Kentucky area of the Twin Registry of the National Research Council-National Academy of Sciences, who participated in the National Heart and Lung Institute Twin Study, were also studied (10). To be admitted to the study, a twin pair had to be in good general health and without historical evidence of significant organic disease. There were 20 malc and 28 female MZ twin pairs and 12 male and 11 female DZ twin pairs in the juvenile group, which included 3 Negro and 68 Caucasian twin pairs. The 80 adult twin pairs, of which 38 were $\mathrm{MZ}$ and 42 were $\mathrm{DZ}$, were all Caucasian men. The occupations of the adult twins as well as the parents of the juvenile twins varied from professional to semiskilled labor.

Measurement of bone mass. Measurements of bone mass and width were performed on the right midshaft radius at a point one-third of the distance from the radial styloid process to the olecranon with a Norland-Cameron Bone Mineral Analyzer (Norland Associates, Inc., Ft. Atkinson, Wis.). This machine utilizes the principles of photon absorptiometry as reported by Cameron and Sorenson (6). A collimated beam of monoenergetic photons $\left({ }^{125} \mathrm{I}\right)$ is passed through the forearm and the resulting attenuation is monitored with a suitable detector. The tissue cover of the forearm is made uniform by application of tissue-equivalent material around the limb to provide flat parallel surfaces above and below. The source and detector are moved across the limb, and the resulting absorption curve can be related to the total bone mineral per unit length of bone being scanned. One passage of source and detector across the radius is considered one measurement (one scan). The instrument automatically integrates the absorption curve and provide estimates of bone mass in grams per centimeter and width of bone being scanned in centimeters. The machine was standardized to a known phantom before each subject was measured. The precision and utilization of this machine in our laboratory have been previously reported (11). In the study population, at least two consecutive measurements of bone mass and width were made in each subject without repositioning the arm between measurements. If the difference in values for replicate measurements for mass or width were greater than 0.05 units, two additional measurements were made. The four values were then evaluated for outlying observations (12) and the mean value of the valid replicate measurements was used in the subsequent analyses.

Determination of zygosity. Zygosity was determined by physical similarities, dermatoglyphic analyses, and typing of 15 polymorphic serum, salivary, and erythrocytic factors, which included ABO, Rh, MNS, Kell, P, Duffy, and Kidd blood types, $\mathrm{Hp}$ and $\mathrm{Tf}$ serum factors, AP, $\mathrm{PGM}_{1}, \mathrm{G} 6 \mathrm{PD}$, and 6-PGD red cell enzyme systems, and Amy and Se salivary factors.

Data analysis. The variation of intrapair differences in bone mass, bone width, height, and weight were computed for $\mathrm{MZ}$ and $\mathrm{DZ}$ groups in young and adult twins and compared by analysis of variance with the $F$ ratio as a test of significant differences. Also, heritability estimates were computed by two methods. The first method (8) uses the equation

$h^{2}=(\text { variance within } \mathrm{DZ} \text { - variance within } \mathrm{M} Z)^{\prime}{ }^{\prime}$

variance within $\mathrm{DZ}$,

where $h^{2}$ is the measure of heritability. The significance of this estimate can be tested by the variance ratio:

$F=$ Variance within DZ/Variance within MZ.

The second measure of heritability utilized the intraclass correlation coefficients $(r)$ in $\mathrm{MZ}$ and $\mathrm{DZ}$ twins (9):

$$
H=\frac{r_{\mathrm{MZ}}-r_{\mathrm{DZ}}}{1-r_{\mathrm{DZ}}}
$$

In practice, the two estimates of heritability usually show reasonably close agreement.

\section{RESULTS}

Measurement crror. Replicate measurements were more variable in the juvenile group, as evidenced by the number of times the criteria for making more than two measurements was incurred (average of 2.5 measurements per individual). Only two consecutive measurements were made on adult twins. The measurement error variances were $0.000539 \mathrm{~g}^{2} / \mathrm{cm}^{2}$ for mass and $0.00982 \mathrm{~cm}^{2}$ for width in the juvenile twins. For adult twins, the measurement error variances were 0.00133 $\mathrm{g}^{2} / \mathrm{cm}^{2}$ for mass and $0.000798 \mathrm{~cm}^{2}$ for width. In neither the juvenile nor the adult group was a significant difference in measurement error found between $M Z$ and $\mathrm{DZ}$ twins.

Effect of age. The distribution of mean values of bone mass and bone width by age, in the juvenile and adult twins, respectively, are shown in Figs. 1 and 2 . Both mass $(M)$ and width $(W)$ increased with age in the juvenile group $\left(b_{M}=0.0532 \pm \operatorname{SE~} 0.0027, b_{W}=\right.$ $0.0402 \pm 0.0032)$. The regression coefficients for $\mathrm{DZ}$ twins $\left(b_{\mathrm{w}-\mathrm{Dz}}=0.0641 \pm 0.0054, \quad b_{\mathrm{w}-\mathrm{Dz}}=0.0543 \pm 0.0067\right)$ were significantly $(P<0.01)$ higher than those for the $\mathrm{MZ}$ twins $\left(b_{\mathrm{M}-\mathrm{MZ}}=0.0457 \pm 0.0022, \quad b_{\mathrm{w}-\mathrm{MZ}}=0.0308 \pm\right.$ 0.0030 ). This probably reflects the slightly greater average age $(12.1 \mathrm{yr})$ of the $\mathrm{DZ}$ twins compared to $\mathrm{MZ}$ twins (11.3 yr); consequently, the $\mathrm{DZ}$ twin data are probably affected to a greater extent by the adolescent growth spurt. In the adult twins there was no significant change in either mass $\left(b_{M}=-0.0038 \pm\right.$ $0.0040)$ or width $\left(b_{w}=0.0014 \pm 0.0035\right)$ in the age range studied (Fig. 2), and there was no significant difference in mean bone mass or width in $M Z$ or $\mathrm{DZ}$ twins. Because of the significant age effect in the juvenile twins, the two sets of data were analyzed separately.

Effect of sex. All of the adult twins were male veterans of World War II; thus only the juvenile 


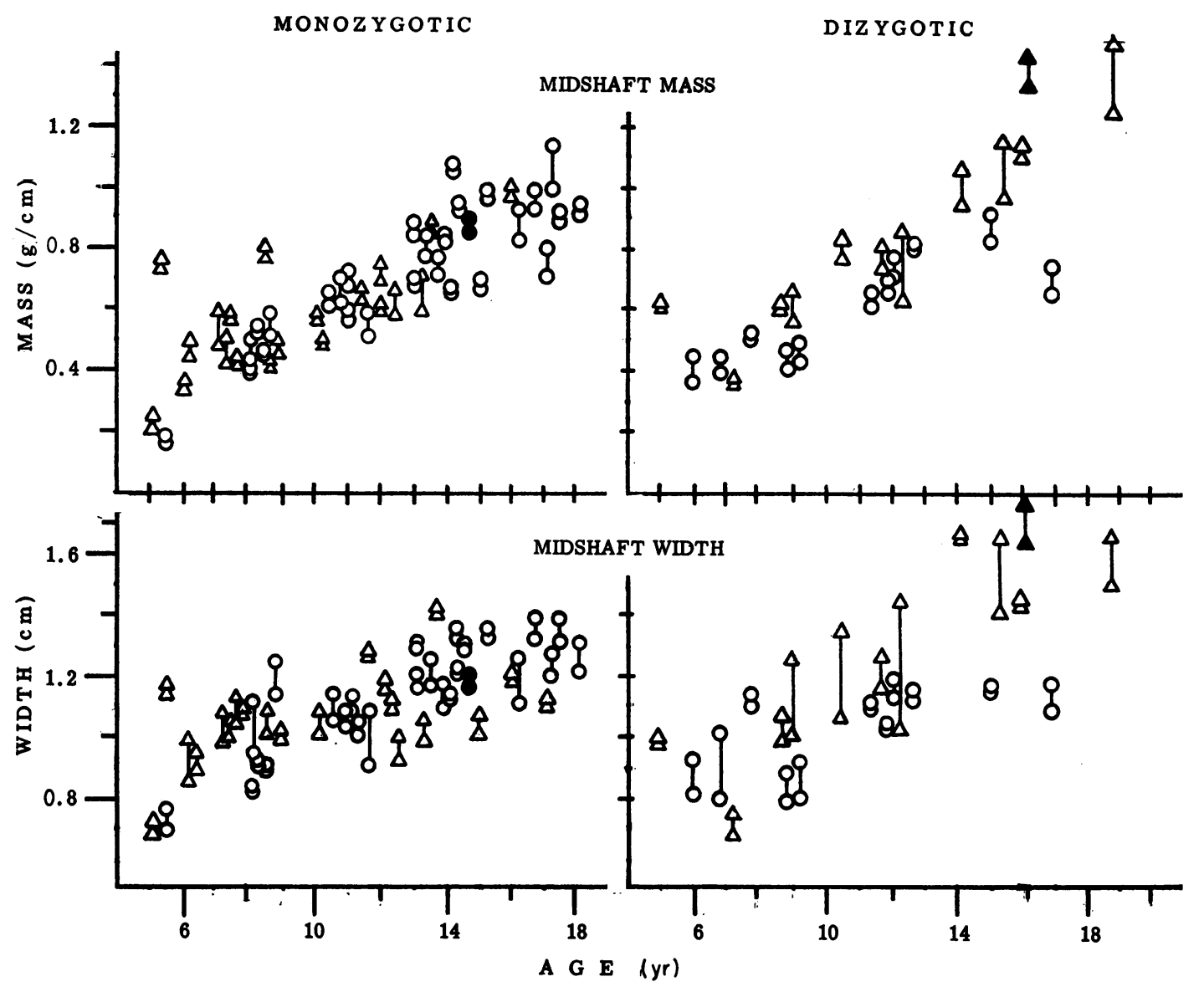

FIGURE 1 The distribution of bone mass and bone width values in juvenile twins plotted against age. Each point is the mean of duplicate measurements. Each twin pair is connected with a vertical line unless the values overlap. The lengths of the vertical lines are a measure of the intrapair differences. $\Delta=$ Caucasian boy, $\boldsymbol{\Delta}=$ Negro boy, $\mathrm{O}=$ Caucasian girl, $\bullet=$ Negro girl.

twins were analyzed for sex effect. When the two zygosity classes were pooled, there was no significant difference in the regression coefficients for bone mass and width with age in boys and girls $\left(b_{M} 0^{*}=0.0553 \pm\right.$ $0.0050, b_{\mu}$ ㅇ $=0.0448 \pm 0.0060$, and $b_{w} \sigma^{*}=0.0517 \pm 0.0047$, $b_{w}+=0.0399 \pm 0.0051$ ), although males had higher values for both variables. When the data were adjusted for differences in units of measurement, these observations on age and sex effect on mass and width agreed closely with those reported by Mazess and Cameron (13).

Genetic analysis of bone mass and width in juvenile twins. The distribution of intrapair differences in the juvenile twins is shown graphically in Figs. 1, 3, and 4. The data are summarized numerically in Table I, along with similar analyses for two additional interrelated variables, height and weight. The variance within DZ twin pairs for mass and width was four times greater than the variance within $M Z$ twin pairs, providing evidence for a significant genetic influence on both traits. Heritability estimates for the four traits, based on two different formulae $(8,9)$ ranged from 0.22 to 0.74 in the juvenile twins.

Genetic analysis of bone mass and width in adult twins. The distribution of intrapair differences for adult twins is shown graphically in Figs. 2, 3, and 4. As with the juvenile twins, the variances within $\mathrm{DZ}$ twins for mass and width were significantly greater than those within $\mathrm{MZ}$ twins $(P<0.025$ and $P<0.05)$, but the $F$ ratios were not as large (Table $\mathrm{I}$ ). Thus, these data provide further evidence for a significant genetic influence on both traits. The calculated heritability estimates for the two bone variables and height and weight ranged from 0.26 to 0.80 .

Interrelationships among height, weight, bone mass, and width. Interrelationships of the four variables in the juvenile and adult twins are shown in Tables II and III. Height and weight are highly correlated variables, 

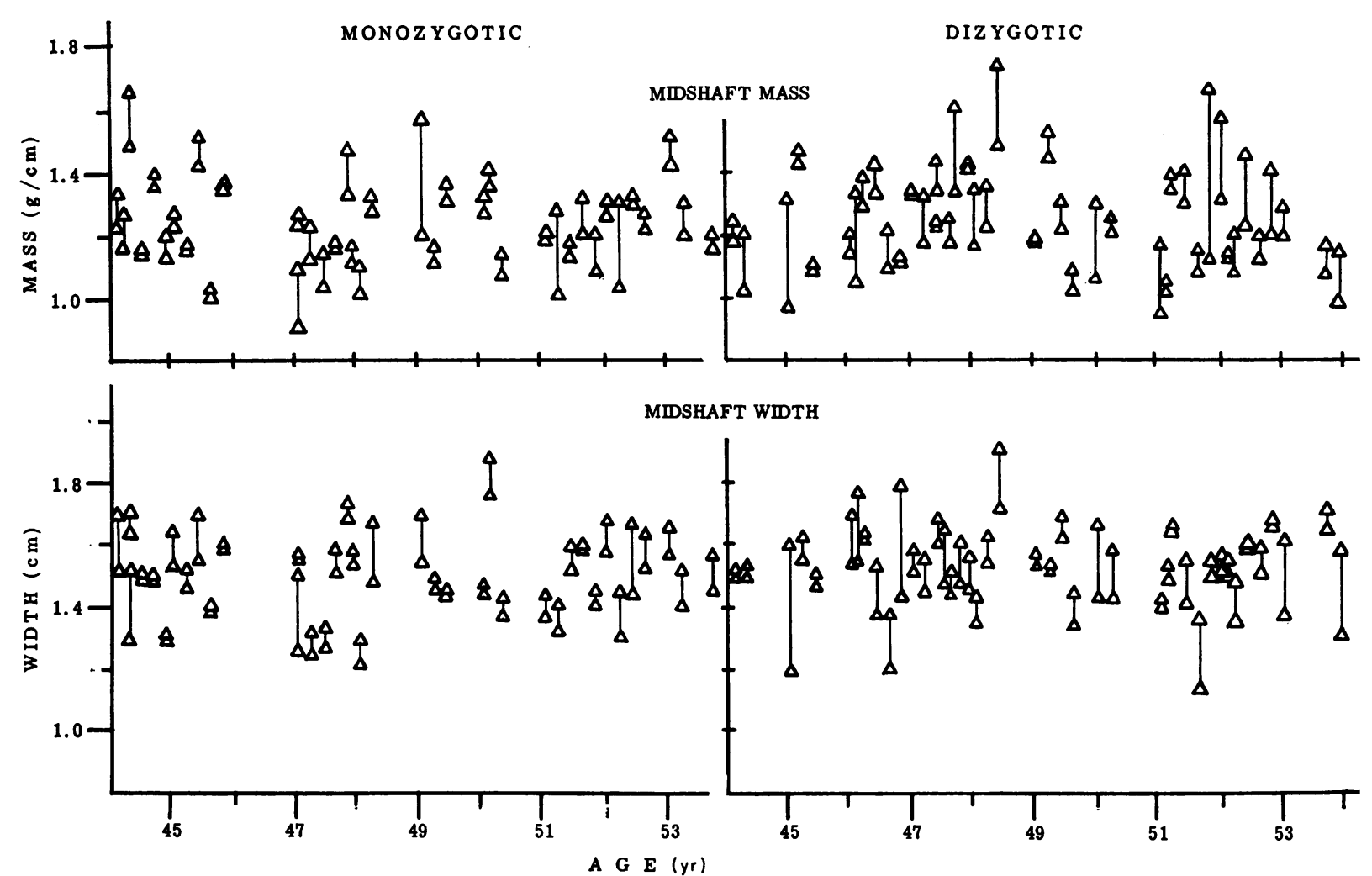

Figure 2 The distribution of bone mass and width in adult twins plotted against age. The symbols are the same as for Fig. 1.

and adjustment of either trait by regression analysis for the other reduces the evidence for a residual genetic effect, as judged by the magnitude of the $F$ ratios. The effect is most striking among the juvenile twins, where growth is not yet complete. Also in juveniles, bone mass and width are interrelated variables, and the effect on the $F$ ratios of correcting either bone variable for height or weight is relatively small in comparison with adjustment of one bone variable for the other. In the adult twins, in contrast to the juvenile twins, adjustment of the measurements of one bone variable for the second bone variable increases the $F$ ratios of the former.

\section{DISCUSSION}

The concept of individual differences (possibly genetic) in skeletal tissue dates at least as far back as 430 B.C. On viewing the terrain 40 years after the battle of Pelusium, the Greek historian Herodotus (14) noted that: ". . . if you strike the Persian skulls, even with a pebble, they are so weak that you break a hole in them; but the Egyptian skulls are so strong that you may smite them with a stone and you will scarcely break them in." Racial and sexual differences in bone mass have been reported by several investigators using different techniques $(7,15,16)$. It is well established that Negro men have high bone mass values and Caucasian women have low values at maturity. These differences, which are presumably genetic in origin, correlate well with the clinical observation that osteoporosis is much more common in the Caucasian woman than in any other race and sex combination. Garn (16, 17) has studied parent-offspring correlations and $\mathrm{MZ}$ twin correlations of cortical bone thickness and concluded that skeletal mass appears to be largely genetically determined.

Human bone mass, defined in this study as the integrated absorption curve of a bone scan of the right radius, is a continuously distributed metric trait. An impressive number of genetic disorders showing simple Mendelian inheritance are known that profoundly affect bone growth and mineral metabolism in ways that would clearly be reflected in the measurement we have made. It seems reasonable to ask, then, whether some component of the variation in bone mass in normal subjects may have a genetic basis. Twin studies provide a useful method for resolving phenotypic variation into its genetic $\left(V_{G}\right)$ and environmental $\left(V_{E}\right)$ components. The twin 


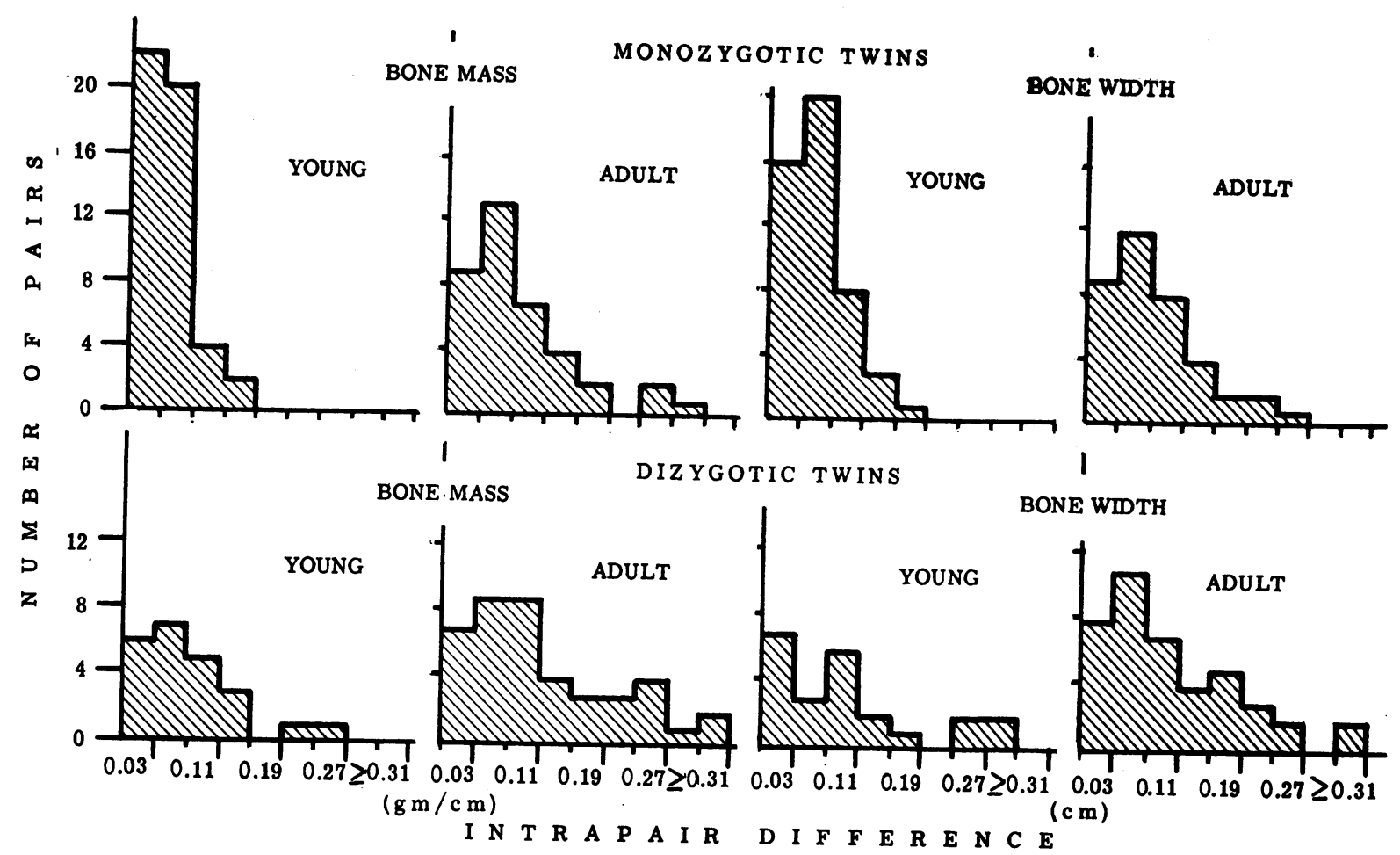

FIGURE 3 Histograms of the intrapair differences in bone mass and bone width in juvenile and adult twins.

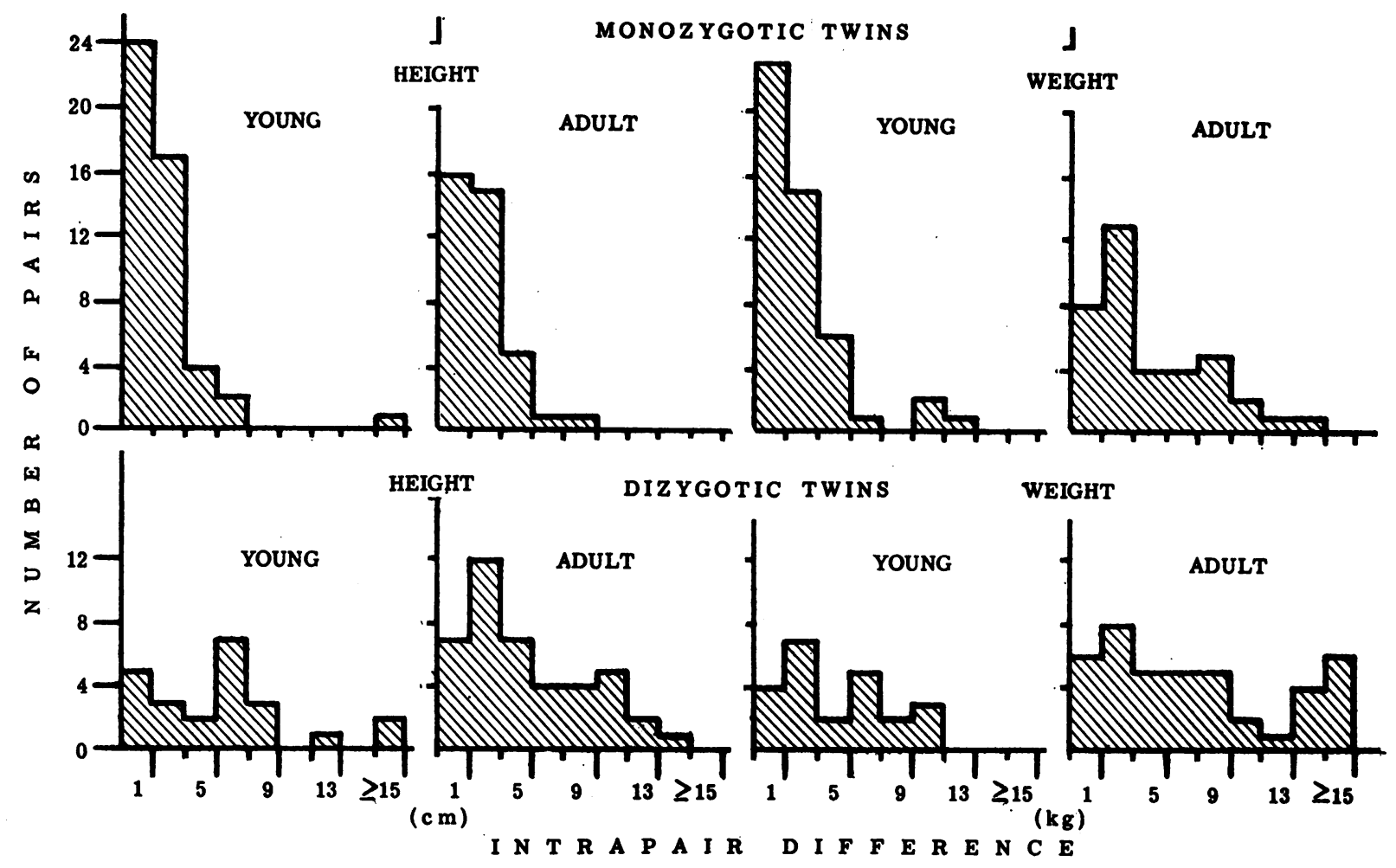

Figure 4 Histograms of the intrapair differences in height and weight in juvenile and adult twins. 
TABLE I

Intrapair iariance, Intraclass Correlation Coefficients, and Heritability Estimates for Height, Weight, Bone Mass, and Bone Width in Juvenile and Adult Twins

\begin{tabular}{|c|c|c|c|c|c|c|c|c|c|c|c|c|c|c|}
\hline \multirow[b]{4}{*}{ Variable } & \multicolumn{5}{|c|}{ Monozygotic twins } & \multicolumn{5}{|c|}{ Dizygotic twins } & \multirow{2}{*}{\multicolumn{2}{|c|}{$F$ test }} & \multirow{3}{*}{\multicolumn{2}{|c|}{$\begin{array}{c}\text { Estimate } \\
\text { of } \\
\text { heritability }\end{array}$}} \\
\hline & \multirow{3}{*}{$\begin{array}{c}\text { Number } \\
\text { of } \\
\text { pairs }\end{array}$} & \multirow{3}{*}{$\begin{array}{c}\text { Mean } \\
\text { values }\end{array}$} & \multicolumn{2}{|c|}{ Variance } & \multirow[b]{3}{*}{$r_{\mathrm{MZ}}$} & \multirow{3}{*}{$\begin{array}{c}\text { Number } \\
\text { of } \\
\text { pairs }\end{array}$} & \multirow{3}{*}{$\begin{array}{c}\text { Mean } \\
\text { values }\end{array}$} & \multicolumn{2}{|c|}{ Variance } & \multirow[b]{3}{*}{$r_{112}$} & & & & \\
\hline & & & Within & Between & & & & Within & Between & & \multirow[b]{2}{*}{ Ratio } & \multirow{2}{*}{$\begin{array}{c}P \\
\text { value }\end{array}$} & & \\
\hline & & & pairs & pairs & & & & pairs & pairs & & & & $h^{2}$ & $H$ \\
\hline \multicolumn{15}{|l|}{ Height, $\mathrm{cm}$} \\
\hline Juvenile & 48 & 147 & 6.31 & 656.6 & 0.980 & 23 & 150.4 & 30.13 & 762.27 & 0.924 & 4.77 & $<0.001$ & 0.79 & 0.74 \\
\hline Adult & 38 & 173 & 4.36 & 73.2 & 0.884 & 42 & 173.6 & 19.96 & 50.28 & 0.422 & 4.58 & $<0.001$ & 0.78 & 0.80 \\
\hline \multicolumn{15}{|l|}{ Weight, $\mathrm{kg}$} \\
\hline Juvenile & 48 & 40 & 6.42 & 401.6 & 0.968 & 23 & 44.0 & 17.57 & 598.00 & 0.948 & 2.74 & $<0.005$ & 0.63 & 0.43 \\
\hline Adult & 38 & 76 & 18.37 & 176.0 & 0.806 & 42 & 77.6 & 50.45 & 160.75 & 0.513 & 2.75 & $<0.005$ & 0.63 & 0.60 \\
\hline \multicolumn{15}{|c|}{ Bone mass, $\mathrm{g} / \mathrm{cm}$} \\
\hline Juvenile & 48 & 0.6 .3 & 0.0013 & 0.0695 & 0.962 & 23 & 0.74 & 0.0052 & 0.1581 & 0.936 & 4.00 & $<0.001$ & 0.75 & 0.41 \\
\hline Adult & 38 & 1.25 & 0.0069 & 0.0332 & 0.698 & 42 & 1.25 & 0.0137 & 0.0371 & 0.451 & 1.99 & $<0.025$ & 0.49 & 0.36 \\
\hline \multicolumn{15}{|c|}{ Bone width, $\mathrm{cm}$} \\
\hline Juvenile & 48 & 1.06 & 0.0021 & 0.0436 & 0.905 & 23 & 1.15 & 0.0091 & 0.1400 & 0.878 & 4.33 & $<0.001$ & 0.77 & 0.22 \\
\hline Adult & 38 & 1.50 & 0.0057 & 0.0313 & 0.684 & 42 & 1.52 & 0.0104 & 0.0224 & 0.353 & 1.82 & $<0.05$ & 0.45 & 0.51 \\
\hline
\end{tabular}

model assumes that variation within $\mathrm{DZ}$ twin pairs $\left(V_{\mathbf{w D Z}}\right.$ is attributable to both environmental and genetic factors,

$$
V_{\mathrm{wDz}}=V_{E}+V_{G}
$$

while differences within $\mathrm{MZ}$ twin pairs reflect environmental differences exclusively, since these individuals are genetically identical:

$$
V_{\mathrm{wMz}}=V_{\boldsymbol{B}}
$$

The demonstration that the intrapair differences of $\mathrm{DZ}$ twins are significantly greater than those of $M Z$ twins provides presumptive evidence for a genetic influence on the trait in question. The model assumes that the environmental differences between $M Z$ twins are comparable to those of $\mathrm{DZ}$ twins and that the total variance of $\mathrm{MZ}$ and $\mathrm{DZ}$ twins are comparable. We made no attempt to assess environmental similarities of the two types of twins. The total variances of $\mathrm{MZ}$ and $\mathrm{DZ}$ adult twins were quite similar, but among the juvenile group, $D Z$ twins were somewhat more variable, probably reflecting the greater range in age and the higher mean age of this group. With these reservations is mind, the data showed that in both of the juvenile and the adult groups, the intrapair differences in $\mathrm{DZ}$ twins for both mineral content and width were significantly greater than those found in $\mathrm{MZ}$ twins.

The variance within $\mathrm{DZ}$ twin pairs may be further subdivided to show the effects of genetic-environmental interactions and to distinguish between genetic factors that have additive $\left(V_{A}\right)$ and dominance $\left(V_{D}\right)$ effects, giving

$$
V_{\mathrm{wDZ}}=V_{E}+V_{G E}+V_{D}+V_{A},
$$

and

$$
V_{\mathrm{w} M}=V_{E},
$$

where $V_{G E}$ is the genetic-environmental interaction resulting from environmental differences among twin pairs, $V_{D}$ the dominance component of the genetic variance and $V_{A}$ the additive component of the genetic variance.

Additive genetic effects are usually distinguished from dominance effects in humans by comparing full sib and parent-offspring correlations. In the absence of dominance, the genetic correlations of these two groups of relatives should be the same. When present, dominance effects tend to inflate the sib-sib correlation at the expense of the parent-offspring correlation. In practice, the age adjustments necessary to compare metric data in parents and offspring often complicate the analysis, and, as pointed out by Wolf (18), the technique does not take into account systematic environmental changes that may have occurred between one generation and the next. We have made no attempt to separate additive and dominance effects in the present study. Resolution of additive and dominance effects in members of the same generation would be possible by comparing the similarities of the full-sib and half-sib offspring of identical twins (19) and might provide further insight into the genetic control of bone mass.

The genetic-environmental interaction component of variation is of great potential importance to the physician because it is a measure of the extent to which individual genetic differences interact with factors in the environment to cause phenotypic variation. Presumably, traits with a large genetic-environmental component of varia- 
TABLE II

Interrelationships of Hereditary Effects on Height, Weight, Bone Mass, and Bone Width in Juvenile Twins

(48 $M Z$ and $23 \mathrm{DZ}$ )

\begin{tabular}{|c|c|c|c|c|}
\hline \multirow[b]{2}{*}{ Variable } & \multicolumn{4}{|c|}{ Within pair variance adjusted for } \\
\hline & Height & Weight & $\begin{array}{l}\text { Bone } \\
\text { mass }\end{array}$ & $\begin{array}{l}\text { Bone } \\
\text { width }\end{array}$ \\
\hline \multicolumn{5}{|l|}{ Height } \\
\hline $\mathrm{DZ}$ & $30.13^{*}$ & 15.25 & 25.72 & 27.52 \\
\hline $\mathrm{MZ}$ & $6.31^{*}$ & 5.73 & 5.90 & 6.33 \\
\hline$F$ & $4.77^{*}$ & 2.66 & 4.35 & 4.35 \\
\hline$P$ & $<0.001^{*}$ & $<0.005$ & $<0.001$ & $<0.001$ \\
\hline \multicolumn{5}{|l|}{ Weight } \\
\hline $\mathrm{DZ}$ & 8.89 & $17.57^{*}$ & 11.16 & 13.83 \\
\hline $\mathrm{MZ}$ & 5.83 & $6.42^{*}$ & 3.94 & 5.68 \\
\hline$F$ & 1.52 & $2.74^{*}$ & 2.83 & 2.43 \\
\hline$P$ & $>0.10$ & $<0.005^{*}$ & $<0.005$ & $<0.01$ \\
\hline \multicolumn{5}{|l|}{ Bone mass } \\
\hline $\mathrm{DZ}$ & 0.0045 & 0.0033 & $0.0052^{*}$ & 0.0011 \\
\hline $\mathrm{MZ}$ & 0.0012 & 0.0008 & $0.0013^{*}$ & 0.0006 \\
\hline$F$ & 3.75 & 4.12 & $4.00^{*}$ & 1.83 \\
\hline$P$ & $<0.001$ & $<0.001$ & $<0.001^{*}$ & $<0.05$ \\
\hline \multicolumn{5}{|c|}{ Bone width } \\
\hline $\mathrm{DZ}$ & 0.0083 & 0.0071 & 0.0021 & $0.0091^{*}$ \\
\hline $\mathrm{MZ}$ & 0.0021 & 0.0019 & 0.0010 & $0.0021^{*}$ \\
\hline$F$ & 3.95 & 3.74 & 2.10 & $4.33^{*}$ \\
\hline$P$ & $<0.001$ & $<0.001$ & $<0.025$ & $<0.001^{*}$ \\
\hline
\end{tabular}

* Unadjusted values.

tion would be most susceptible to therapeutic intervention if the appropriate environmental influences could be matched to specific genotypes. Because of the great difficulty involved in controlling the environment in experimental studies of human subjects, measurement of the influence of genetic-environmental interactions on quantitative traits has been extremely difficult, although many monogenic prototypes are known where these interactions are of great clinical significance (20).

Although the present data are not conclusive, they give some indication that genetic-environmental interactions may have an important influence on bone mass. If we assume that the twins are exposed to a relatively uniform environment while they live at home but to completely different environments when they leave home, we would expect these environmental differences to augment the intrapair variance of both $\mathrm{MZ}$ and $\mathrm{DZ}$ twins, while the $\mathrm{DZ}$ differences might also be increased by genetic-environmental interactions. These effects could lead to a decrease in the apparent degree of genetic determination as judged by the significance of the variance
TABLE III

Interrelationships of Hereditary Effects on Height, Weight, Bone Mass, and Bone Width in Adult Twins (32 $\mathrm{MZ}$ and $42 \mathrm{DZ}$ )

\begin{tabular}{|c|c|c|c|c|}
\hline \multirow[b]{2}{*}{ Variable } & \multicolumn{4}{|c|}{ Within-pair variance adjusted for } \\
\hline & Height & Weight & $\begin{array}{l}\text { Bone } \\
\text { mass }\end{array}$ & $\begin{array}{l}\text { Bone } \\
\text { width }\end{array}$ \\
\hline \multicolumn{5}{|l|}{ Height } \\
\hline $\mathrm{DZ}$ & $19.96^{*}$ & 16.89 & 18.36 & 17.54 \\
\hline $\mathrm{MZ}$ & $4.36^{*}$ & 4.19 & 4.48 & 4.47 \\
\hline$F$ & $4.57^{*}$ & 4.03 & 4.10 & 3.92 \\
\hline$P$ & $<0.001^{*}$ & $<0.001$ & $<0.001$ & $<0.001$ \\
\hline \multicolumn{5}{|l|}{ Weight } \\
\hline $\mathrm{DZ}$ & 42.69 & $50.45^{*}$ & 44.63 & 46.80 \\
\hline $\mathrm{MZ}$ & 17.60 & $18.37^{*}$ & 18.79 & 18.64 \\
\hline$F$ & 2.42 & $2.75^{*}$ & 2.37 & 2.51 \\
\hline$P$ & $<0.005$ & $<0.005^{*}$ & $<0.005$ & $<0.005$ \\
\hline \multicolumn{5}{|l|}{ Bone mass } \\
\hline $\mathrm{DZ}$ & 0.0126 & 0.0121 & $0.0137^{*}$ & 0.0105 \\
\hline $\mathrm{MZ}$ & 0.0071 & 0.0071 & $0.0069^{*}$ & 0.0042 \\
\hline$F$ & 1.77 & 1.70 & $1.99^{*}$ & 2.5 \\
\hline$P$ & $<0.05$ & $<0.05$ & $<0.025^{*}$ & $<0.005$ \\
\hline \multicolumn{5}{|c|}{ Bone width } \\
\hline $\mathrm{DZ}$ & 0.0092 & 0.0097 & 0.0080 & $0.0104^{*}$ \\
\hline $\mathrm{MZ}$ & 0.0059 & 0.0058 & 0.0035 & $0.0057^{*}$ \\
\hline$F$ & 1.56 & 1.67 & 2.28 & $1.87^{*}$ \\
\hline$P$ & $<0.10$ & $<0.10$ & $<0.01$ & $<0.05^{*}$ \\
\hline
\end{tabular}

* Unadjusted values.

ratio between $M Z$ and $D Z$ twins. In the present study, the intrapair variance of both bone mass and bone width was greater in the adult twins of both types than in the juvenile twins, and $F$ tests and the conventional heritability estimates generally suggested a low degree of genetic determination in the adult twins. To test the hypothesis that these changes did indeed result from genetic-environmental interactions, we examined in greater detail the changes in intrapair differences in the juvenile twins with age. Our model assumes that twins who still live together will be exposed to similar but constantly changing environmental influences as they grow up. Under this model, increases in the intrapair differences of growing $M Z$ twins could arise only from minor within-pair environmental differences. On the other hand, since DZ twins are genetically dissimilar, intrapair genetic-environmental differences would be expected to arise even from changes in the environment to which both twins are exposed and would tend to increase the intrapair variance of $\mathrm{DZ}$ twins as they grow. Regression of the intrapair differences in bone mass of 
the juvenile twins on age yielded $b=0.0013(P>0.05)$ for the MZ twins and $b=0.0083(P<0.025)$ for the $\mathrm{DZ}$ pairs. Thus the intrapair differences appeared to increase with age in both the $M Z$ and $D Z$ pairs, but the change was significant only in the case of the $D Z$ twins. No significant changes in the intrapair differences of bone width of the juvenile twins were found for either the $M Z$ or $D Z$ groups. As noted previously, geneticenvironmental interactions would seem to be a plausible interpretation for the observed changes in bone mass.

The interesting interrelationships between bone mass and bone width deserve comment. In the juvenile twins, where there was much variation among pairs because adult stature had not been achieved, the two traits were highly correlated and adjustment of one trait for variation in the other had the effect of markedly reducing the residual evidence for genetic determination of the initial trait, as judged by the magnitude of the variance ratio. This finding is consistent with a high degree of commonality in the effects of the genetic factors that influence bone mass and width during the period of life when bone growth is not yet complete. In contrast, the variance ratios in adult twins were both increased by adjustment of the data for the other bone variable, suggesting that when growth and differentiation are complete, the effects of independent genetic determinants of bone width and mass can be detected. As an illustrative analogy, we might suppose that a mutant gene determining onychodystrophy has, along with many other genes, a general influence on limb bud development of the 10 -mm embryo, but its specific effect would not be manifested until the nails begin to differentiate. In a similar manner, the individual expression of genes affecting bone mass, apart from bone size, may not occur until after bone growth is complete.

It is appropriate to relate the results of this investigation to the etiology of the disease osteoporosis. The disease is clinically significant only when fracture occurs, usually of the vertebral body, hip, or wrist. There are many factors that may increase the risk of fracture, but the total amount of bone mass present appears to be a major determinant of the risk of fracture (5). Population surveys suggest that women developing fractures lose bone mass at a similar rate to age-matched controls $(5,21)$. Hence the amount of bone mass at maturity would appear to be an important determinant of the amount of residual bone mass present in later years. This study provides evidence that bone mass at maturity has significant genetic determinants. And it therefore seems reasonable to postulate that genetic factors, either by acting alone or by interacting with environmental variables known to influence mineral metabolism, may predispose to the development of osteoporosis.

\section{ACKNOWLEDGMENTS}

The authors acknowledge the excellent technical assistance of J. Walt, C. Flanary, P. Winter, and D. Huntzinger.

This investigation was supported in part by USPHS grant No. AM-07126 and Contract No. NIH-71-2307 with the National Heart and Lung Institute, National Institutes of Health, and by a grant from the John A. Hartford Foundation. The facilities of the Research Computer Center of Indiana University Purdue University at Indianapolis (I.U.P.U.I.) were used for much of the statistical analyses.

\section{REFERENCES}

1. McKusick, V. A. 1960. Heritable Disorders of Connective Tissue. The C. C. Mosby Company, St. Louis, Mo., 2nd edition. 199.

2. Burnett, C. H., C. E. Dent, C. H. Harper, and B. J. Warren. 1964. Vitamin D-resistant rickets. Analysis of 24 pedigrees with hereditary and sporadic cases. $\mathrm{Am}$. J. Med. 36: 222.

3. Johnston, C. C., Jr., N. Lavy, T. Lord, F. Vellios, A. D. Merritt, and W. P. Deiss, Jr. 1968. Osteopetrosis. A clinical, genetic, metabolic, and morphologic study of the dominantly inherited, benign form. Medicine (Baltimore). $47: 149$.

4. Elmore, S. M., W. E. Nance, B. J. McGee, M. E. Montmollin, and E. Engel. 1966. Pycnodysostosis with familial chromosome anomaly. Am. J. Med. 40: 273.

5. Newton-John, H. F., and D. B. Morgan. 1970. The loss of bone with age, osteoporosis, and fractures. Clin. Orthop. Related Res. 71:229.

6. Cameron, J. R., and J. Sorenson. 1963. Measurement of bone mineral in vivo: An improved method. Science (Wash. D. C.). $142: 230$.

7. Johnston, C. C., Jr., D. M. Smith, P. Yu, and W. P. Deiss, Jr. 1968. In vivo measurement of bone mass in the radius. Metab. Clin. Exp. 17: 1140.

8. Clark, P. J. 1955. The heritability of certain anthropometric characteristics as ascertained from measurements of twins. Am. J. Hum. Genet. 8: 49.

9. Holzinger, K. J. 1929. The relative effect of nature and nurture influences on twin differences. J. Educ. Psych. $20: 241$.

10. Feinleib, M., R. J. Havlik, P. O. Kwiterovich, J. Tillotson, and R. C. Garrison. 1970. The National Heart Institute Twin Study. Acta Genet. Med. Gemellol. 19: 243.

11. Johnston, C. C., Jr., D. M. Smith, W. E. Nance, and S. Bevan. 1973. Evaluation of radial bone mass by the photon absorption technique. Excerpta Med. Int. Congr. Ser. 270: 28.

12. Dixon, W. J., and F. J. Massey, Jr. 1957. Introduction to Statistical Analysis. McGraw-Hill Book Co., New York, 2nd edition. 275.

13. Mazess, R. B., and J. R. Cameron. 1972. Growth of bone in school children: comparison of radiographic morphometry and photon absorptiometry. Growth. 36: 77.

14. Herodotus, 430 B.C. The Persian Wars. Book III, Chapter 12.

15. Meema, H. E. 1963. Cortical bone atrophy and osteoporosis as a manifestation of aging. Am. J. Roentgenol. Radium Ther. Nucl. Med. 89 : 287.

16. Garn, S. M. 1970. Population differences and familyline differences in cortical thickness. In The Earlier 
Gain and Later Loss of Cortical Bone. Charles C Thomas, Publisher, Springfield, I11. 55.

17. Garn, S. M. 1963. Human biology and research in body composition. Ann. N. Y. Acad. Sci. 110: 429.

18. Wolf, B. 1952. Environmental effects in quantitative inheritance. In Quantitative Inheritance. E. C. R. Reve and $\mathrm{C}$. $\mathrm{H}$. Waddington, editors. Agricultural Research Council, Her Majesty's Stationery Office, London. 81.

19. Nance, W. E., M. Nakata, T. D. Paul, and P. Yu. 1973. The use of twin studies in the analysis of pheno- typic traits in man. In Congenital Defects: New Directions in Research. D. T. Janerich, R. G. Skalko, and I. H. Porter, editors. Academic Press, Inc., New York. In press.

20. Vesell, E. S. 1969. Recent progress in pharmacogenetics. Adv. Pharmacol. Chemother. $7: 1$.

21. Smith, D. M., and C. C. Johnston, Jr. 1972. In vivo measurement of bone mass: its use in demineralized states such as osteoporosis. J. Am. Med. Assoc. 219: 325. 